Journal of Physical Science, Vol. 32(1), 39-56, 2021

\title{
Fabrication of Polydimethylsiloxane (PDMS) Dense Layer on Porous Polyethersulfone (PES) Hollow Fibre Membrane with Varying Dip Coating Parameters
}

\author{
Amir Ikmal Hassan, Abdul Latif Ahmad, ${ }^{*}$ Zulfida Mohamad Hafis Mohd Shafie \\ and Nur Dina Zaulkiflee
}

School of Chemical Engineering, Universiti Sains Malaysia, Engineering Campus, 14300 Nibong Tebal, Pulau Pinang, Malaysia

*Corresponding author: chlatif@usm.my

Published online: 25 April 2021

To cite this article: Hassan, A. I. et al. (2021). Fabrication of polydimethylsiloxane (PDMS) dense layer on porous polyethersulfone (PES) hollow fibre membrane with varying dip coating parameters. J. Phys. Sci., 32(1), 39-56. https://doi.org/10.21315/jps2021.32.1.4

To link to this article: https://doi.org/10.21315/jps2021.32.1.4

\begin{abstract}
Polydimethylsiloxane (PDMS) is commonly used as a separating layer in gas separation membrane, hydrocarbon separation process, pervaporation and as a viable gutter layer in composite membrane fabrication. A methodical dip coating technique was used to fabricate PDMS dense layer on porous polyethersulfone (PES) hollow fibre membrane. Dip coating parameters such as coating speed (5-15 $\left.\mathrm{mm} \mathrm{s}^{-1}\right)$ and holding time (10-900 s) were varied using an automated dip coating machine. Scanning electron microscopy (SEM) and Fourier transform infrared (FTIR) spectroscopy characterisation were also conducted to investigate the membrane morphology and confirmed the presence of a coating on the membrane surface. Gas permeation performance test was carried out with $\mathrm{CO}_{2}$ and $\mathrm{N}_{2}$ under transmembrane pressure of 1 to 3 bars after membrane coating was finalised. The test results indicated that the coating speed inflicted less influence in the overall performance with a selectivity of 0.86. Gas permeance also exceeded 20,000 GPU mark at a lower speed, suggesting that a single coating at this speed range could not fully coat the porous PES fibres. Nevertheless, reduction of permeance with increasing speed indicates an improvement in the PDMS layer thickness. On the other hand, holding time in the coating solution showed a slight effect on membrane performance compared to the coating speed. However, the membrane exhibits drop in permeance reaching below 1,000 GPU at high holding time, suggesting a more complete coverage of the support with the PDMS layer. Hypothetically, it is caused by the increased viscosity during the PDMS crosslinking reaction as time passed, allowing more PDMS solution to be retained on the PES fibre's surface.
\end{abstract}

Keywords: Polydimethylsiloxane, polyethersulfone, hollow fibre, dip coating, PDMS 


\section{INTRODUCTION}

Composite membranes are not relatively new in membrane technology. There are various ways of producing this type of membrane including dip coating, film casting and spin coating. ${ }^{1}$ The purpose of composite fabrication includes forming a dense selective layer for separation purposes and sealing surface defects. Nevertheless, different coating methods will result in different effects on the membrane. Among the coating methods, dip coating is the simplest to be conducted and is suitable for composite fabrication in hollow fibre. Controlling the dipping time, speed and number of the consecutive coating layer can be made easily through this method. ${ }^{2}$ It also allows coating with respective thickness without the high cost. ${ }^{3}$

The selection of polymer coating is one of the vital steps in fabricating composite membrane. The selection is also determined by the application of the membrane, whether on liquid-based separation or gas separation. Polydimethylsiloxane (PDMS) possesses such characteristic to be used in both applications. ${ }^{4}$ It is commonly used in membrane distillation, gas separation and pervaporation. ${ }^{3,5-9}$ The addition of dense PDMS top layer on a porous support layer creates resistance for diffusing species, allowing separation of different permeants. On the other hand, high hydrophobic properties of PDMS allows antiwetting membrane research to be conducted.

Several researchers have studied the use of PDMS in gas permeation such as Merkel et al. ${ }^{10}$ From the study, $\mathrm{CO}_{2}$ permeability was noted to achieve 3800 Barrer, one of the highest gas permeability values for this gas. Nevertheless, such feat is achievable provided the coating on the membrane is uniform. ${ }^{6}$ On the other hand, research works on membrane gas absorption and membrane distillation require the coating to be porous to minimise transport resistance. ${ }^{11-13}$ Hence, in this study, the influence of dip coating parameters on the resulting PDMS coated PES hollow fibre membrane would be performed. Gas separation test using $\mathrm{CO}_{2} / \mathrm{N}_{2}$ gases would be conducted to study the effect of different dip-coating parameters on the resulting coating layer.

\section{EXPERIMENTAL}

\subsection{Materials}

For the fibre substrate fabrication, polyethersulfone (PES) (Ultrason E6020P, BASF) was used as the substrate polymer material while N-methyl-2-pyrrolidone (NMP) (99.5\%, Merck, Germany) was used as the substrate's solvent. On the 
other hand, PDMS (hydroxy-terminated, viscosity 2550-3570 cSt, Aldrich) was used to fabricate the dense coating layer with N-heptane (anhydrous 99\%, SigmaAldrich) as its solvent. Dibutyltin dilaurate (DBD) (95\%, Aldrich) and tetraethyl orthosilicate (TEOS) (reagent grade 98\%, Aldrich) was used as the catalyst and crosslinking agent, respectively during PDMS coating.

\subsection{Fabrication of PES Hollow Fibre Membrane Substrate}

PES flakes were dried in a vacuum oven under the temperature of $110^{\circ} \mathrm{C}$ at -60 bar for about $5 \mathrm{~h}$. The dried flakes were then mixed with NMP for $18 \mathrm{~h}$ at $60^{\circ} \mathrm{C}$, 700 RPM using a mechanical stirrer. Once fully mixed, the dope solution was placed in an ultrasonicator bath for degassing purpose, for $1 \mathrm{~h}$. The ratio of PES to NMP was maintained at 0.19 . HF membranes were then spun through dry jet/wet spinning method, with filtered water as non-solvent. Coagulation bath was let to flow freely to maintain minimum non-solvent accumulation. Ambient temperature and relative humidity were naturally maintained at $23.4^{\circ} \mathrm{C} \pm 0.1^{\circ} \mathrm{C}$ and $64.8 \% \pm$ $0.8 \%$, respectively in a closed room with air conditioner, and ventilation turned on. Purified nitrogen gas was used to pressurise the dope solution. The summary of other spinning parameters is as listed in Table 1 .

Table 1: Spinning system parameters.

\begin{tabular}{|c|c|}
\hline Parameter & Value \\
\hline Dope speed & 10 RPM \\
\hline Bore fluid speed & $1.80 \mathrm{ml} \mathrm{min}^{-1}$ \\
\hline Bore fluid composition & $50 / 50 \mathrm{v} / \mathrm{v} \mathrm{H}_{2} \mathrm{O} / \mathrm{NMP}$ \\
\hline Dope pressure & $1.5 \mathrm{bar}$ \\
\hline Air gap distance & $10 \mathrm{~cm}$ \\
\hline Take-up speed & 7.2 RPM \\
\hline Spinneret diameters & $\mathrm{OD}=0.42 \mathrm{~mm}$ \\
\hline Bore fluid outlet diameters & $\mathrm{OD}=0.19 \mathrm{~mm} ; \mathrm{ID}=0.12 \mathrm{~mm}$ \\
\hline
\end{tabular}

After the spinning process, spun fibres were immersed in water for $24 \mathrm{~h}$ to promote full solvent exchange, with the water changed after the first $3 \mathrm{~h}$. Then, the fibres were dried in air for several days. 


\subsection{PDMS Dip Coating of PES Hollow Fibre Membrane}

The fibre coating solution was prepared using the formulation adapted from Salih et al. ${ }^{14}$ PDMS, DBD and TEOS were mixed in the ratio of $3: 1: 1$ by weight in heptane, with PDMS concentration of $3 \mathrm{wt} \%$. The mixed solution was sonicated in an ultrasonicator bath for a few minutes before being used. For hand coat studies, the fibres were dipped manually into the PDMS solution and left to soak for a designated time (1 $\mathrm{min}, 5 \mathrm{~min}$ and $10 \mathrm{~min}$ ). The process was repeated for five-time dipping cycles. For machine coating, thin steel rods were used to straighten the membranes anchored with steel stapler bullets at each end to hold it into position tightly. Each membrane length was fixed at about $10 \mathrm{~cm}$. The steel rod was then hanged and locked at the automated dip coating machine. The prepared PDMS solution was then poured into the underneath measuring cylinder for the dip-coating procedure. Speed of coating and holding time were varied between $5-15 \mathrm{~mm} \mathrm{~s}^{-1}$ and 5-900 s respectively to observe the differences in PDMS coating between the samples. The procedures were repeated three times for different membrane fibres on the same selected parameter to ensure uniform data sampling. The coated fibres were then left in the oven to be completely dry at $70^{\circ} \mathrm{C}$ overnight. The summary of the samples prepared, and the sample's IDs are tabulated in Table 2.

Table 2: List of samples prepared.

\begin{tabular}{lccc}
\hline Sample ID & Number of coating & Speed of coating $\left(\mathrm{mm} \mathrm{s}^{-1}\right)$ & Holding time (s) \\
\hline PES_1_5_5 & 1 & 5 & 5 \\
PES_1_10_5 & 1 & 10 & 5 \\
PES_1_15_5 & 1 & 15 & 5 \\
PES_1_10_10 & 1 & 10 & 10 \\
PES_1_10_20 & 1 & 10 & 20 \\
PES_1_10_200 & 1 & 10 & 200 \\
PES_1_10_900 & 1 & 10 & 900 \\
\hline
\end{tabular}

\subsection{Characterisation Methodology}

The membrane sample's surface and cross-sectional morphology were characterised using the scanning electron microscope (SEM, Hitachi TM 3000). All samples were thin-coated with gold/palladium using a sputter coater (Quorum SC7620) for $90 \mathrm{~s}$ before analysis. For the cross-section, the hollow fibre was fractured using liquid nitrogen. The micrograph of the surface pores of the uncoated pristine fibres was analysed using ImageJ software using the method 
described elsewhere. ${ }^{15}$ Fourier transform infrared (FTIR) spectroscopy (Thermo Scientific Nicolet Nexus 670) was performed to determine the functional groups present on the membrane surface. Samples were scanned over the wavelength range of $2700 \mathrm{~cm}^{-1}$ to $3235 \mathrm{~cm}^{-1}$. Average spectrums of 32 scans were recorded per sample characterised.

\subsection{Module Preparation and Permeation Measurement}

A single strand of the coated membrane was potted into a module. The potted fibre was then tested for $\mathrm{CO}_{2}$ and $\mathrm{N}_{2}$ gas separation performance at 1-3 bar transmembrane pressure in dead-end mode. Permeate flow rate was measured using bubble soap flowmeter connected to the permeate side of the module. All experiments were conducted in room temperature. The gas permeance, $\frac{P_{i}}{l}$, was then calculated by using the following equation:

$$
\frac{P_{i}}{l}=\frac{Q}{A \Delta P} \times 10^{6}
$$

where $Q$ is the volumetric flow rate of gas permeated through the membrane $\left[\mathrm{cm}^{3}(\mathrm{STP}) / \mathrm{s}\right], \Delta P$ is the transmembrane pressure difference $(\mathrm{cmHg})$, and $A$ is the effective membrane surface area. The gas permeance of membrane was taken in gas permeation units, GPU $\left[1 \mathrm{GPU}=1 \times 10^{-6} \mathrm{~cm}^{3}(\mathrm{STP}) / \mathrm{cm}^{2} . \mathrm{s} . \mathrm{cm} \mathrm{Hg}\right]$. The gas selectivity, $\alpha$ was calculated using the following equation:

$$
\alpha \frac{i}{j}=\frac{\left(\frac{P_{i}}{l}\right)}{\left(\frac{P_{j}}{l}\right)}
$$

where $i$ and $j$ represent the gas of interest.

\section{RESULTS AND DISCUSSION}

\subsection{Characterisation and Performance of Uncoated PES Hollow Fibre Membrane}

Figure 1 illustrates the surface and cross-section morphology of uncoated PES hollow fibre membrane. The cross-section micrograph shows two divided, distinctive layers where small fingerlike pores extrude from the outer and bigger fingerlike pores in the inner surface. The measured fibre dimensions and characteristics of the neat PES hollow fibre membrane are presented in Table 3. Membrane bore and outer layer are in circular shape with the surface layer 
being relatively thin compared to the overall thickness measured. The fabricated substrate is shown to have consistent characteristic throughout the study.
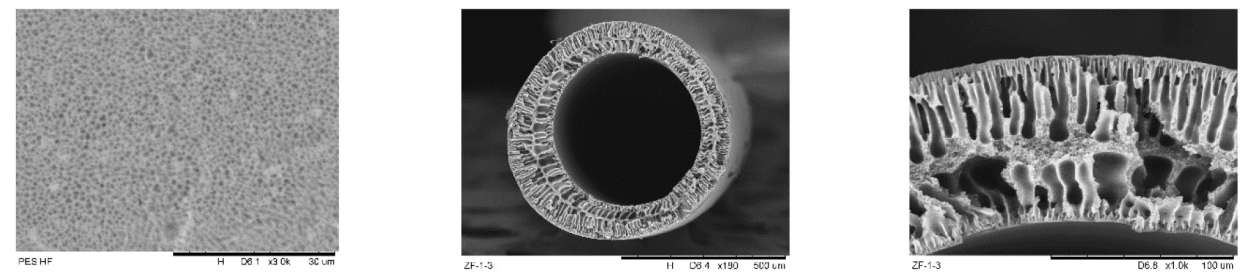

Figure 1: SEM micrograph of pristine (uncoated) PES hollow fibre membrane. From left to right: surface at $3000 \mathrm{X}$ magnification, cross-section at $180 \mathrm{X}$ magnification, and cross-section at $1000 \mathrm{X}$ magnification.

Table 3: Fabricated fibre's dimension and surface characteristics.

\begin{tabular}{lc}
\hline Parameter & Value \\
\hline Outer diameter $(\mathrm{mm})$ & $0.664 \pm 0.003$ \\
Inner diameter $(\mathrm{mm})$ & $0.454 \pm 0.002$ \\
Thickness $(\mathrm{mm})$ & $0.210 \pm 0.002$ \\
Surface porosity $(\%)$ & $20.39 \pm 0.01$ \\
Average surface pore size $(\mu \mathrm{m})$ & $0.539 \pm 0.001$ \\
Surface pore density $\left(\right.$ per $\left.\mathrm{mm}^{2}\right)$ & $705 \pm 4$ \\
\hline
\end{tabular}

Membrane surface pores are further analysed through image analysis. The surface pore distribution is presented in Figure 2. The result suggested that the surface pores range from $0.1 \mu \mathrm{m}$ to $2.0 \mu \mathrm{m}$ in diameter with the average sizes of the pores between $0.4 \mu \mathrm{m}$ to $0.5 \mu \mathrm{m}$. Surface pores ranging less than $0.1 \mu \mathrm{m}$ diameter are too small to be measured accurately, and are therefore excluded from this study. 


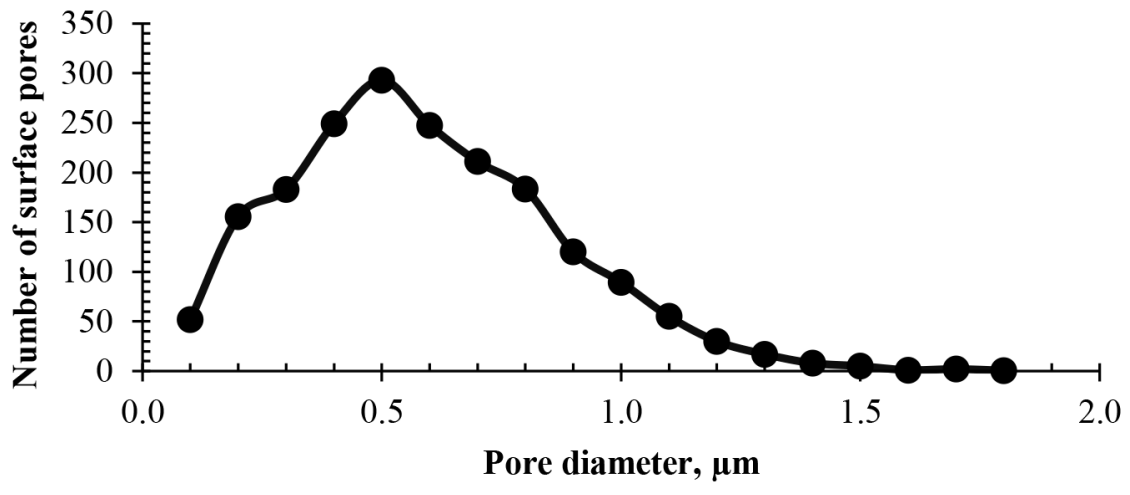

Figure 2: Surface pore size distribution of the uncoated PES hollow fibre membrane.

Figure 3 demonstrates the increasing $\mathrm{N}_{2}$ gas flux across the neat fibres with increasing transmembrane pressure. It can be observed that the flux is linearly increasing, reaching $20,000 \mathrm{~cm}^{3}$ (STP) $/ \mathrm{cm}^{2} . \mathrm{s}$, which suggests the mechanical viability of the fibres in this study. This high gas flux also directly correlates with the high pore counts noted previously, enabling the membrane to be highly permeable with minimal resistance ${ }^{16}$ It is important to note that no significant sign of compaction or burst at high pressure is seen during testing. Hence the hollow fibre substrate is suitable for PDMS coating and tested for gas permeation in this work.

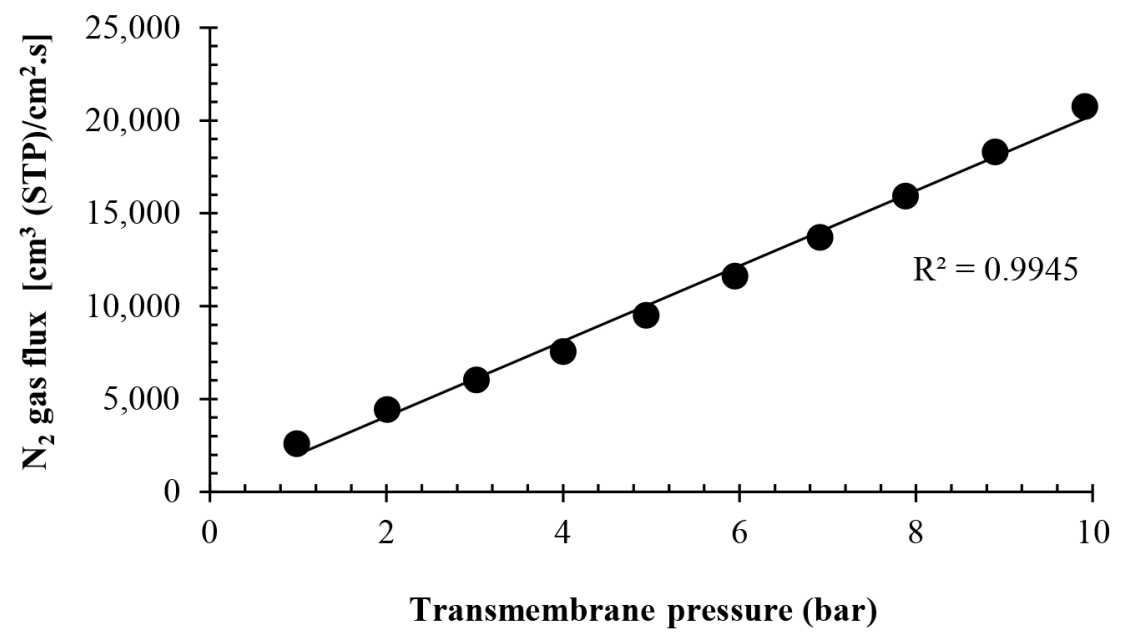

Figure 3: Flux performance with increasing transmembrane pressure with $\mathrm{N}_{2}$ as feed. 


\subsection{Characterisation of Manually Dip-coated PES Hollow Fibre Membrane}

As Figure 4 shows, the dipping/holding time minimally affects the surface coating for hand-coated fibres. This might be related to the porous nature of the fibres. Larger pore size is more susceptible to surface coating's pore penetration by the liquid's capillary forces, thus forming an additional thick resistance layer inside the porous structure. ${ }^{17}$ Not to mention, large surface pore could also limit the amount of PDMS solution that can adhere to the membrane's surface. ${ }^{18}$ Nevertheless, as the solution becomes glutinous after $15 \mathrm{~min}$, this suggested that crosslinking of PDMS is occurring and transfixed on the membrane's surface. Coating characteristics might change drastically near to this time as the solution's viscosity can be affected by the rate of crosslinking degree. ${ }^{17}$
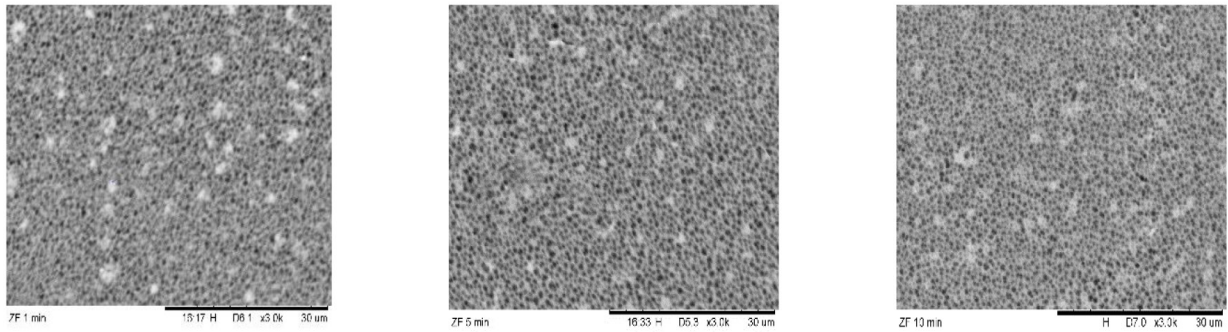

Figure 4: SEM micrograph of hand-coated PES hollow fibre membrane at different dipping/holding time. From left to right: $1 \mathrm{~min}, 5 \mathrm{~min}$ and $10 \mathrm{~min}$, all at $3000 \mathrm{X}$ magnification.

On the other hand, the number of coating played an important parameter whereby PDMS was seen clearly (Figure 5) when the number of coatings increased due to the increase in coating layer thickness. ${ }^{2}$ However, this coating was uneven due to the hand-coated nature of this work where the speed of coating was inconsistent. Nevertheless, this type of coating allows the membrane's surface porosity to be minimally affected which would be an advantage for applications requiring augmented surface hydrophobicity such as membrane gas absorption and membrane distillation, owing to the hydrophobic nature of PDMS (water contact angle $\left.>90^{\circ}\right) \cdot{ }^{19,20}$ 

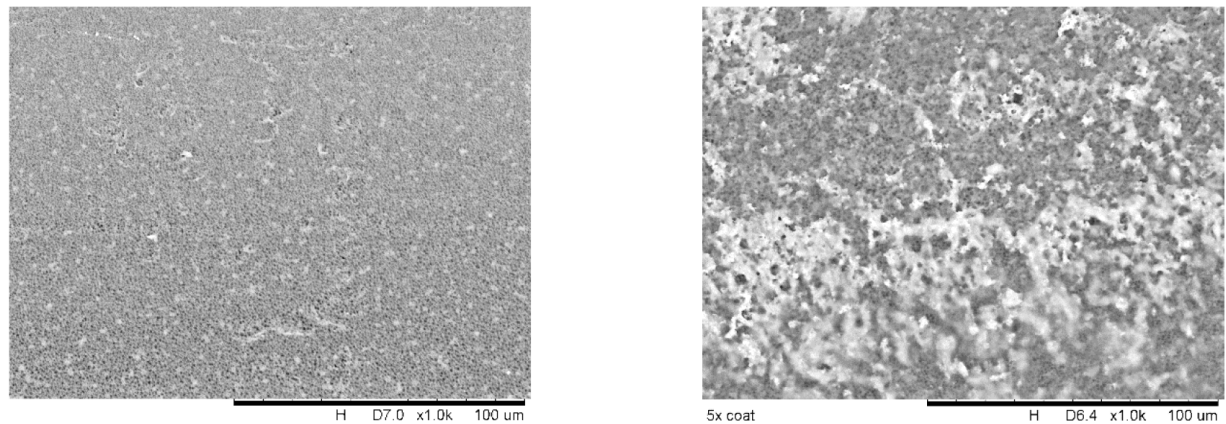

Figure 5: SEM micrograph of hand-coated PES hollow fibre membrane at different dipping cycles: 1-time coating (left) and 5-time coating (right). All at $1000 \mathrm{X}$ magnification with 10 min fibre holding time.

\subsection{Preliminary Machine Dip-coated PES Hollow Fibre Membrane}

Figure 6 represents the SEM surface and cross-section of single coated PES fibre using an automated dip-coating machine. However, the micrograph does not profoundly prove the existence of the PDMS coating layer on the surface. This could be due to the insufficient number of coating, creating only a very thin PDMS layer on the surface. It is also possible that the coating is scattered on the surface, hence not creating any visible layer. Hence, the FTIR spectroscopy study was employed to support further the evidence of the PDMS thin layer formation.
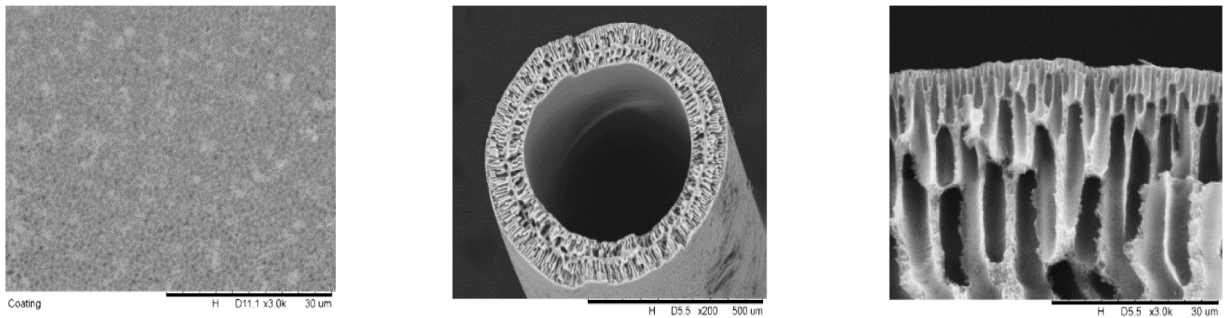

Figure 6: SEM micrograph of surface and cross-section PES single-coated PDMS hollow fibre membrane. From left: Surface at 3000X magnification, cross-section at 200X magnification, and cross-section at 3000X magnification.

The FTIR spectra of both pristine and PDMS coated fibres were illustrated in Figure 7. There is a slight $\mathrm{C}-\mathrm{H}$ stretch vibration of $\mathrm{CH}_{3}$ in the transmittance peaks in the region of 2950 to 2965 for PDMS coated compared to pristine PES. This stretch is further emphasised in Figure 7 (bottom). This $\mathrm{CH}_{3}$ peaks are only 
available in PDMS and are absent in PES, which confirms PDMS adhesion on the PES substrate. ${ }^{21-24}$ Although, the peak is quite nominal since it is only single coated. This also indicates that the layer is very thin, providing only a weak display of spectroscopy peak.
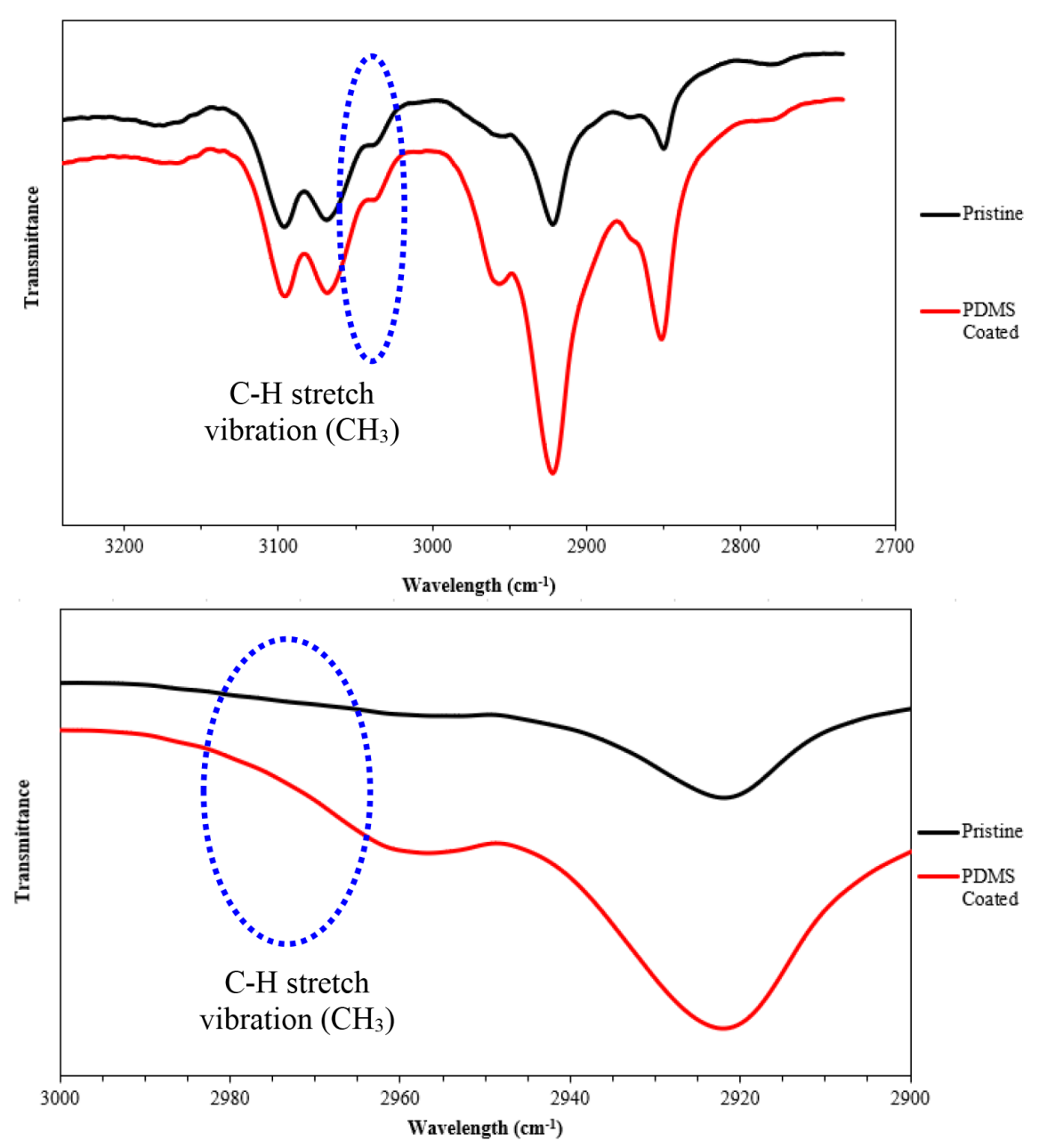

Figure 7: FTIR spectra of (top) full for pristine PES and PDMS coated (bottom) emphasised spectra region.

The fibres were then tested out for $\mathrm{CO}_{2}$ and $\mathrm{N}_{2}$ gas permeance. The result is shown in Table 4. Pristine PES membrane holds higher GPU value as compared with the coated membrane. This directly correlates with the surface condition of the 
membrane. Since it was porous, it allowed more gas to pass through while in coated membrane condition, the GPU drops a bit. ${ }^{8,25}$

Even though the FTIR shows the fibre to be covered by PDMS coating, the layer was not homogeneously distributed across the membrane, seen from the gas selectivity in Table 4. Defects might still be formed at this condition, which limits its application for gas separation. However, at this condition, the fibres might be suited for other application such as membrane distillation or membrane gas absorption.

Table 4: Permeance comparison between pristine and single-coated PES membrane.

\begin{tabular}{lccc}
\hline \multirow{2}{*}{ Membrane } & \multicolumn{2}{c}{ Permeance $(\mathrm{GPU})^{\mathrm{a}}$} & \multirow{2}{*}{ Selectivity $\left(\mathrm{CO}_{2} / \mathrm{N}_{2}\right)$} \\
\cline { 2 - 3 } & \multicolumn{1}{c}{$\mathrm{N}_{2}$} & $\mathrm{CO}_{2}$ & 0.86 \\
Pristine & $23,148.99$ & $19,955.32$ & 0.82 \\
Single coated (PES_1_5_5) & $20,259.35$ & $16,559.87$ & \\
\hline
\end{tabular}

Note: ${ }^{a} 1 \mathrm{GPU}=1 \times 10^{-6}(\mathrm{STP}) / \mathrm{cm}^{2} . \mathrm{s} . \mathrm{cmHg}$

\subsection{Machine Dip-coating - Influence of PDMS Coating Cycle}

As noted in the manually coated fibres in Figure 5, the PDMS layer could be visibly seen when coated five times. However, due to the varying coating speed, the layer formed is not smooth. Similarly, Figure 8 represents the surface SEM of machine coated fibres. It seems that smoother surface can be seen for machine dip-coating compared to the hand-coated fibres, while the pores are less visible between the one-time and five-time coating, suggesting a better coating consistency.
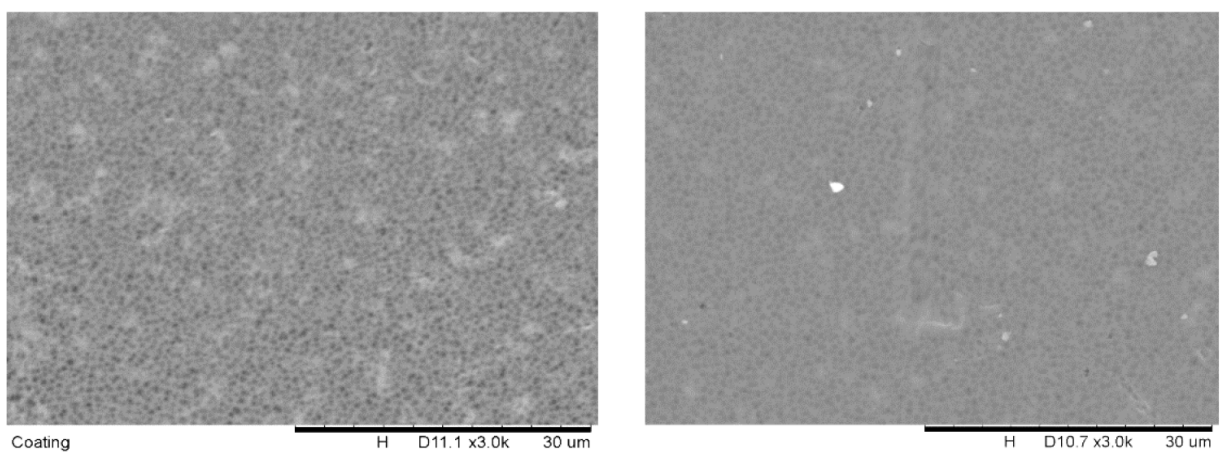

Figure 8: SEM micrograph of single coated and five-time coated PDMS/PES hollow fibre membrane surface at $3000 \mathrm{X}$ magnification. 
The higher number of coating layers correlates to higher thickness of the PDMS layer on the membrane. A study found that, varying the number of coating reaching five times indeed increased the coating layer's thickness. ${ }^{2}$ This leads to a decrease in gas permeance. ${ }^{2}$ The study also shows that a higher number of coating layers results in higher selectivity, especially in the case of $\mathrm{CO}_{2} / \mathrm{N}_{2}$ gas performance. Therefore, it can be expected if such a performance test was conducted in this work, the theory should be as follows. Other than that, any other method of manipulating the thickness of the membrane would also increase the membrane's performance since increasing the number of coating layer subsequently increases the thickness of the coating layer.

\subsection{Machine Dip-coating - Influence of Coating Speed}

The coated hollow fibre membrane was also tested with the pure gases by manipulating the coating speed from $5 \mathrm{~mm} \mathrm{~s}^{-1}$ to $15 \mathrm{~mm} \mathrm{~s}^{-1}$ at $5 \mathrm{~s}$ dipping time, as illustrated in Figure 9. From the figure, we can see that the GPU trend is decreasing as the coating speed increases. A study made by Chen et al. stated that slower coating speed allows the coated membrane to be re-dissolved into the coating solution, which in our case is the PDMS coating solution. ${ }^{26}$ This could be one of the factors of the high permeance of the pure gases on lower coating speed.

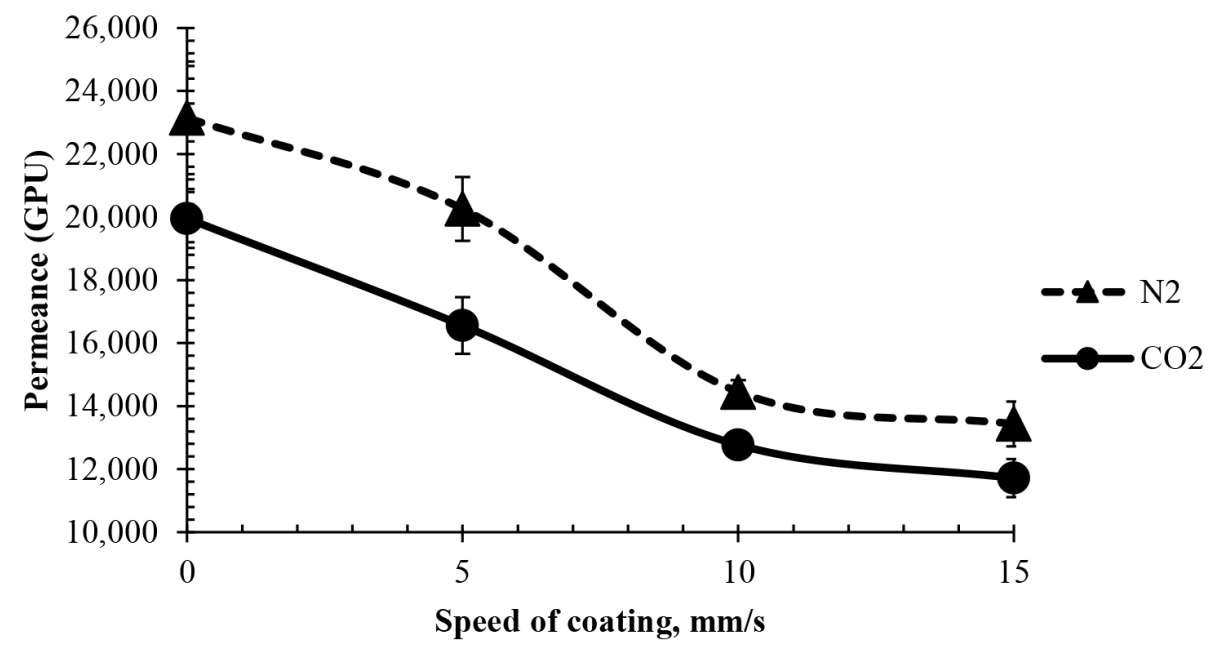

Figure 9: Permeance trend of $\mathrm{N}_{2}$ and $\mathrm{CO}_{2}$ across the PDMS coated membrane with the variation of coating speed. 
Figure 10 shows the selectivity of the fibres on $\mathrm{CO}_{2} / \mathrm{N}_{2}$ gas with respect to the dipcoating speed of the hollow membrane into the PDMS solution. From the figure, the peak selectivity of 0.884 was reached at $10 \mathrm{~mm} \mathrm{~s}^{-1}$. It is significantly low compared with other works such as Madaeni and Naik et al. which are relatively similar in working procedures. ${ }^{2,3}$ This study is more aligned to Lasseuguette et al., which states that lower coating speed resulted in a thinner coating layer, hence higher permeability of gases and inefficient PDMS coating as a selective layer. ${ }^{27}$ However, the minimal difference of selectivity shows that the coating speed parameter was insignificant in maintaining a uniform coating at a low coating cycle.

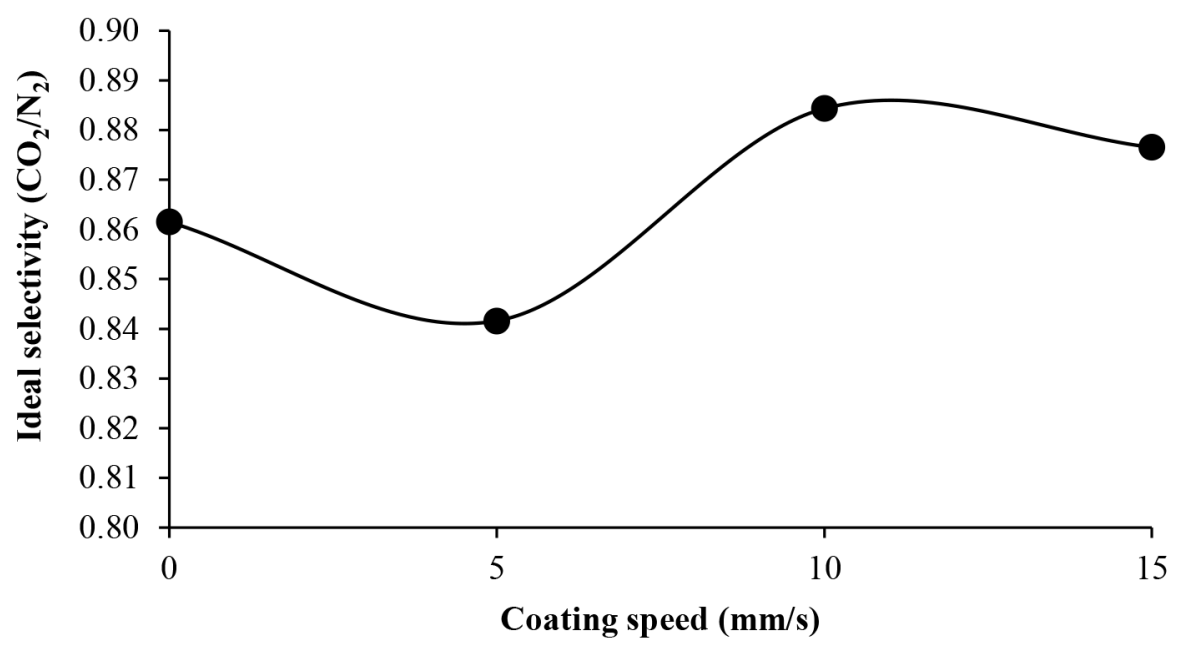

Figure 10: $\mathrm{CO}_{2} / \mathrm{N}_{2}$ selectivity of the samples against variation of coating speed at $5 \mathrm{~s}$ holding time.

In any case, the selectivity of the membranes collectively agrees with the Knudsen selectivity which can be calculated by:

$$
\propto \frac{i}{j}=\sqrt{\frac{M_{j}}{M_{i}}}
$$

where $M$ represents the molecular weight of the gas of interest. In this case, the molecular weights of $\mathrm{CO}_{2}$ and $\mathrm{N}_{2}\left(44.01 \mathrm{~g} \mathrm{~mol}^{-1}\right.$ and $28.01 \mathrm{~g} \mathrm{~mol}^{-1}$, respectively) yield $\mathrm{CO}_{2} / \mathrm{N}_{2}$ Knudsen selectivity of 0.8 . The value is near to the results reported here for pristine membrane $\left(0 \mathrm{~mm} \mathrm{~s}^{-1}\right.$ coating) and all coated membranes at all coating speeds. It can be concluded that the selectivity achieved in this study was the average selectivity for the gases in the Knudsen flow regime. The finding 
confirms that the coating formed by an automated dip-coating machine was not consistent and still did not fully cover the porous PES substrate.

\subsection{Machine Dip-coating - Influence of Membrane Holding Time}

In the previous parameter, the holding time was fixed at $5 \mathrm{~s}$ for every sample. Now, coating speed at $10 \mathrm{~mm} \mathrm{~s}^{-1}$ was fixed, and the change in holding time was studied as a method to form a uniform coating of the membrane. As Figure 11 presents, holding time range from the shortest to longest period possible was chosen to observe the influence of dip coating parameter on the coated membrane. Both $\mathrm{CO}_{2}$ and $\mathrm{N}_{2}$ gases showed similar trend which the permeance peaks at 200 $\mathrm{s}$ holding time. Furthermore, it also displays a significant decrease in permeance peaking at 25,000 GPU to less than 1,000 GPU nearing the gelation of the PDMS coating solution, as discussed in Section 3.2. The increase of holding time would also increase the thickness of the adhered PDMS layer since the solution would be thicker due to increased solution viscosity as the PDMS crosslinking reaction occurred. With a thicker coating layer, the gas permeance would normally decrease. ${ }^{28,29}$ Longer holding time in coating solution also allows more intrusion of PDMS into the pores subsequently increasing the layer thickness as suggested by $\mathrm{Hu}$ et al. ${ }^{18}$ It should be noted that the holding time should not be too long, exceeding the gelation time of PDMS coating solution.

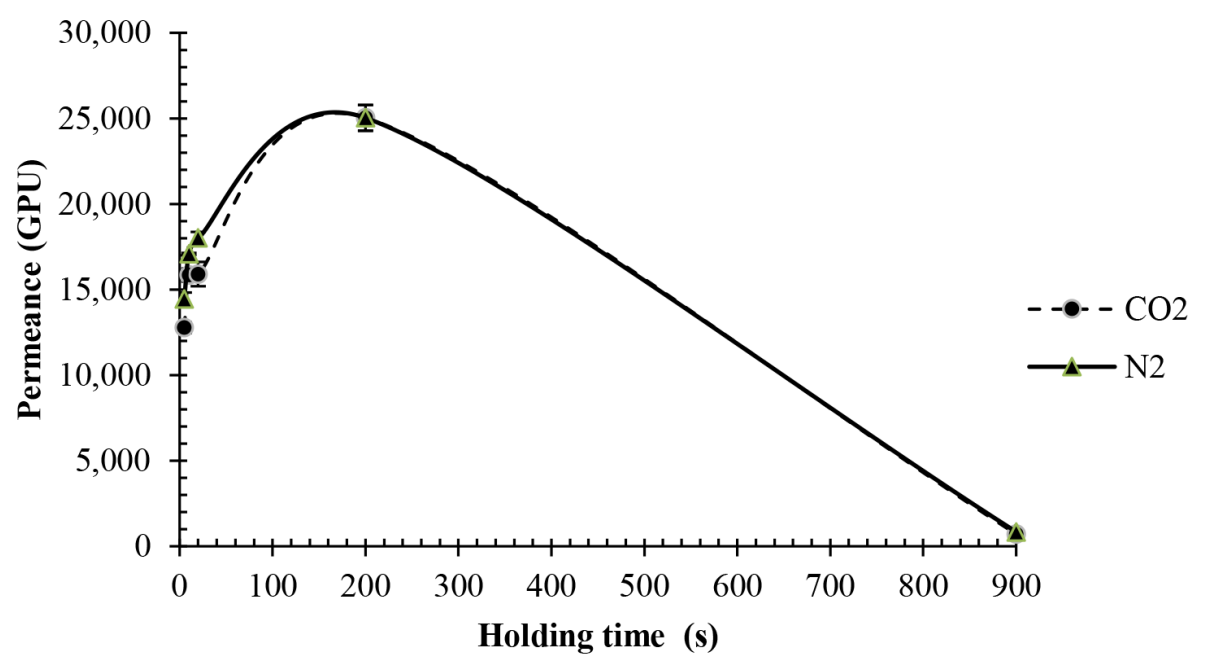

Figure 11: Permeance of $\mathrm{N}_{2}$ and $\mathrm{CO}_{2}$ of PDMS coated hollow fibre membrane against holding time. 
Interestingly, both gases uphold the same permeance at $200 \mathrm{~s}$ and $900 \mathrm{~s}$, which could be a sign that coating is present inconsistently. Theoretically, $\mathrm{CO}_{2}$ should have higher permeability than $\mathrm{N}_{2}$, which has been discussed in depth by previous works. ${ }^{10,28,30}$ Figure 12 represents the selectivity of PDMS coated fibres with different holding time which barely increased from the previous parameter reaching to $0.911 \mathrm{~s}$ at $200 \mathrm{~s}$ mark. This proves that porous PES fibre gas flow is still dictated by the Knudsen regime, indicating that the coating was inconsistent with some pores exposed on the surface. Although there might be a possibility whereby solution-diffusion mechanism and Knudsen diffusion occur in this scenario, the permeance is too high, and the selectivity is too low to consider otherwise. ${ }^{2}$ The tradeoff between permeance and selectivity does not seem to affect the membrane at longer holding time when the coating is conducted in one dipping cycle.

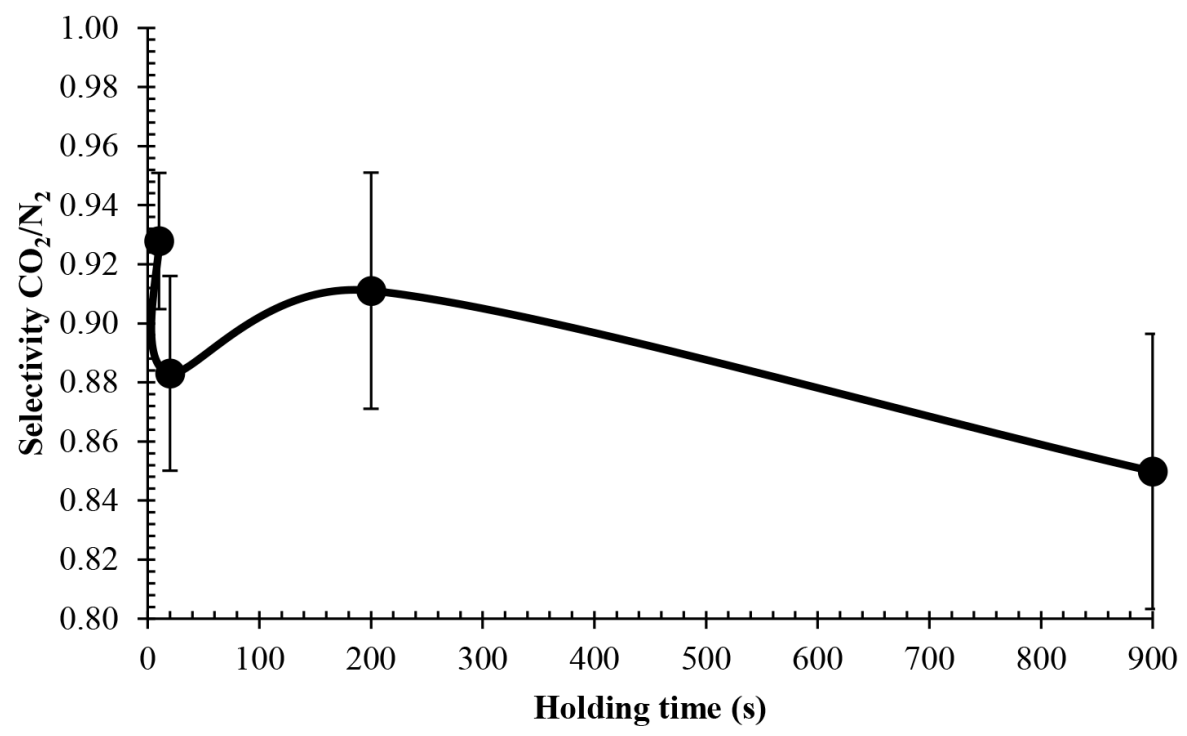

Figure 12: $\mathrm{CO}_{2} / \mathrm{N}_{2}$ selectivity of PDMS coated hollow fibre membrane against increasing holding time.

\section{CONCLUSION}

The coating speed seems to have less impact on the membrane's performance while coating holding time tends to have a slight influence near the PDMS gelation time. With selectivity relative to intrinsic selectivity of PES substrate, it indicates that the Knudsen flow dominates the gas transport mechanism of the 
coated membranes. Membrane pores are still exposed even with the presence of coating, hence producing the performance discussed in this work. In summary, between the parameters chosen for this study, shorter holding time provides more impact on the membrane performance as compared to the speed of coating, while the number of dipping cycles can improve the coating visibility and possibly roughness depending on the membrane applications.

\section{ACKNOWLEDGEMENTS}

The authors are grateful to the funding of the research grant provided by the USMRUI (FRGS Grant - 203.PJKIMIA.6071484).

\section{REFERENCES}

1. Dai, Z., Ansaloni, L. \& Deng, L. (2016). Recent advances in multi-layer composite polymeric membranes for $\mathrm{CO}_{2}$ separation: A review. Green Energy Environ., 1(2), 102-128. https://doi.org/10.1016/j.gee.2016.08.001

2. Madaeni, S. S., Badieh, M. M. S. \& Vatanpour, V. (2013). Effect of coating method on gas separation by PDMS/PES membrane. Polym. Eng. Sci., 53(9), 1878-1885. https://doi.org/10.1002/pen.23456

3. Naik, P. V., Bernstein, R. \& Vankelecom, I. F. J. (2016). Influence of support layer and PDMS coating conditions on composite membrane performance for ethanol/ water separation by pervaporation. J. Appl. Polym. Sci., 133(28), 1-12. https://doi. org/10.1002/app.43670

4. Eduok, U., Faye, O. \& Szpunar, J. (2017). Recent developments and applications of protective silicone coatings: A review of PDMS functional materials. Prog. Org. Coat., 111, 124-163. https://doi.org/10.1016/j.porgcoat.2017.05.012

5. Qin, F. et al. (2014). A PDMS membrane with high pervaporation performance for the separation of furfural and its potential in industrial application. Green Chem., 16(3), 1262-1273. https://doi.org/10.1039/C3GC41867G

6. Shi, E. et al. (2006). Influence of binding interface between active and support layers in composite PDMS membranes on permeation performance. J. Appl. Polym. Sci., 104, 2468-2477. https://doi.org/10.1002/app.25358

7. Madaeni, S. S. \& Hoseini, S. (2009). Fabrication and characterization of PDMS coated PES membranes for separation of ethylene from nitrogen. J. Polym. Res., 16(5), 591-599. https://doi.org/10.1007/s10965-008-9264-5

8. Sari, P. et al. (2019). Simple method to enhance $\mathrm{O}_{2} / \mathrm{N}_{2}$ separation on P84 copolyimide hollow fiber membrane. IOP Conf. Ser. Mater. Sci. Eng., 546(4). https:// doi.org/10.1088/1757-899X/546/4/042042

9. Yave, W. et al. (2010). $\mathrm{CO}_{2}$-Philic polymer membrane with extremely high separation performance. Macromol., 43(1), 326-333. https://doi.org/10.1021/ ma901950u 
10. Merkel, T. C. et al. (1998). Gas sorption, diffusion, and permeation in poly(dimethylsiloxane). J. Polym. Sci. B Polym. Phys., 38, 415-434. https://doi. org/10.1002/(SICI)1099-0488(20000201)38:3<415::AID-POLB8>3.0.CO;2-Z

11. Mohd Shafie, Z. M. H. et al. (2019). Prospect of oxyplus hollow fibre membrane with dense polymethylpentene (PMP) skin as support-gutter layer of thin film composite (TFC) for biogas upgrading. J. Phys. Sci., 30, 179-189. https://doi. org/10.21315/jps2019.30.s2.15

12. Lasseuguette, E., Remigy, J. C. \& Rouch, J. C. (2010). Innovative contactor for $\mathrm{CO}_{2}$ recovery. Paper presented at the Conference for Innovation for Sustainable Production (ISUP2010) Conference, Bruges, Belgium.

13. Eykens, L. et al. (2017). Coating techniques for membrane distillation: An experimental assessment. Sep. Purif. Technol., 193, 38-48. https://doi. org/10.10164/j.seppur.2017.10.070

14. Salih, A. A. M. et al. (2014). Interfacially polymerized polyetheramine thin film composite membranes with PDMS inter-layer for $\mathrm{CO}_{2}$ separation. J. Membr. Sci., 472, 110-118. https://doi.org/10.1016/j.memsci.2014.08.025

15. Mohd Shafie, Z. M. H. et al. (2020). Lithium chloride (LiCl)-modified polyethersulfone (PES) substrate surface pore architectures on thin poly(dimethylsiloxane) (PDMS) dense layer formation and the composite membrane's performance in gas separation. RSC Adv., 10(16), 9500-9511. https:// doi.org/10.1039/D0RA00045K

16. He, M. et al. (2018). Manipulating membrane surface porosity and pore size by in-situ assembly of Pluronic F127 and tannin. J. Memb. Sci., 556, 285-292. https:// doi.org/10.1016/j.memsci.2018.03.087

17. Dong, Z. et al. (2014). High performance ceramic hollow fiber supported PDMS composite pervaporation membrane for bio-butanol recovery. J. Memb. Sci., 450, 38-47. https://doi.org/10.1016/j.memsci.2013.08.039

18. Hu, L. et al. (2018). Optimization of coating solution viscosity of hollow fibersupported polydimethylsiloxane membrane for $\mathrm{CO}_{2} / \mathrm{H}_{2}$ separation. J. Appl. Polym. Sci., 135(5), 1-10. https://doi.org/10.1002/app.45765

19. Park, E. J. et al. (2014). Hydrophobic polydimethylsiloxane (PDMS) coating of mesoporous silica and its use as a preconcentrating agent of gas analytes. Langmuir, 30(34), 10256-10262. https://doi.org/10.1021/la502915r

20. Hadi Yousefi, M. et al. (2017). Investigation of dip-coating parameters effect on the performance of alumina-polydimethylsiloxane nanofiltration membranes for desalination. J. Water Environ. Nanotechnol., 2(4), 235-242. https://doi. org/10.22090/jwent.2017.04.002

21. Ingole, P. G. et al. (2014). Preparation, modification and characterization of polymeric hollow fiber membranes for pressure-retarded osmosis. RSC $A d v$., 4(93), 51430-51439. https://doi.org/10.1039/C4RA07619B

22. Lee, J. et al. (2013). Effect of thermal treatment on the chemical resistance of polydimethylsiloxane for microfluidic devices. J. Micromech. Microeng., 23(3), 035007. https://doi.org/10.1088/0960-1317/23/3/035007 
23. Khan, A. A. et al. (2019). Hybrid organic-inorganic functionalized polyethersulfone membrane for hyper-saline feed with humic acid in direct contact membrane distillation. Sep. Purif. Technol., 210, 20-28. https://doi.org/10.1016/j. seppur.2018.07.087

24. Ge, M. et al. (2020). A "PDMS-in-water" emulsion enables mechanochemically robust superhydrophobic surfaces with self-healing nature. Nanosc. Hor., 5(1), 65-73. https://doi.org/10.1039/C9NH00519F

25. Zulhairun, A. K. et al. (2015). Asymmetric hollow fiber membrane coated with polydimethylsiloxane-metal organic framework hybrid layer for gas separation. Sep. Purif. Technol., 146, 85-93. https://doi.org/10.1016/j.seppur.2015.03.033

26. Chen, H. Z. et al. (2014). High performance composite hollow fiber membranes for $\mathrm{CO}_{2} / \mathrm{H}_{2}$ and $\mathrm{CO}_{2} / \mathrm{N}_{2}$ separation. Int. J. Hydr. Energy, 39(10), 5043-5053. https:// doi.org/10.1016/j.ijhydene.2014.01.047

27. Lasseuguette, E., Rouch, J. \& Remigy, J. (2013). Hollow-fiber coating: Application to preparation of composite hollow-fiber membrane for gas separation. Ind. Eng. Chem. Res., 52(36), 13146-13158. https://doi.org/10.1021/ie401874m

28. Pian, C. et al. (2016). Ceramic hollow fiber-supported PDMS composite membranes for oxygen enrichment from air. Asia-Pac. J. Chem. Eng., 11(3), 460-466. https:// doi.org/10.1002/apj.1972

29. Yoo, M. J. et al. (2018). Ultrathin gutter layer for high-performance thin-film composite membranes for $\mathrm{CO}_{2}$ separation. J. Membr. Sci., 566, 336-345. https:// doi.org/10.1016/j.memsci.2018.09.017

30. Sadrzadeh, M. et al. (2009). Gas permeation through a synthesized composite PDMS/PES membrane. J. Membr. Sci., 342(1-2), 236-250. https://doi. org/10.1016/j.memsci.2009.06.047 